\title{
Marked Directional Skull Asymmetry in the Araucan Horse
}

\author{
Pere M. Parés-Casanova ${ }^{1}$ René Alejandro Crosby-Granados ${ }^{2}$ Fabián Muñoz ${ }^{2}$ \\ Arcesio Salamanca-Carreño ${ }^{2}$ \\ ${ }^{1}$ Department of Animal Science, University of Lleida, Lleida, \\ Catalonia, Spain \\ 2 Facultad de Medicina Veterinaria y Zootecnia, Grupo de \\ Address for correspondence Pere M. Parés-Casanova, PhD, Department \\ of Animal Science, University of Lleida, ETSEA Av. Rovira Roure, 191 Lleida, \\ Catalonia 25198, Spain (e-mail: peremiquelp@ca.udl.cat).
} Investigaciones los Araucos, Universidad Cooperativa de Colombia,

Arauca, Arauca, Colombia

VCOT Open 2020;3:e11-e18.

\begin{abstract}
Keywords

- Araucan

- bilateral asymmetry

- directional asymmetry

- fluctuating asymmetry

Background Deviations from the perfect symmetry of normally bilateral symmetrical characters occur during individual development due to the influence of multiple factors. Fluctuating asymmetry (FA) is the random developmental variation of a trait (or character) that is perfectly symmetrical, on average, across a population. Directional asymmetry (DA) occurs when one side of the pair of body sides is strongly more marked.

Objective We investigated the presence and level of skull FA and DA in the Araucan horse, a breed from East Colombia.

Study Design A sample of 21 skulls belonging to adult animals was studied by means of standard geometric-morphometric methods using 16 landmarks on the dorsal aspect of the crania.

Results Measurements showed a significant DA with a consistent rightward shift of the splanchnocrania.

Conclusions The results of this study raise questions about the influence of masticatory biomechanics on the asymmetric development of the skull, and also about how management and ingesta-specific properties (such as abrasiveness) may influence this asymmetry.
\end{abstract}

\section{Introduction}

Most multi-cellular organisms are bilaterally symmetrical in that they possess a plane across which structures are produced in a paired, but reflected manner. ${ }^{1}$ However, asymmetry is nevertheless widespread, and can be observed at many levels of biological organization. ${ }^{1,2}$ There are three types of bilateral asymmetry: fluctuating asymmetry (FA), anti-symmetry and directional asymmetry (DA). ${ }^{1,3}$ Fluctuating asymmetry is a pattern of bilateral variation where the mean difference between sides for a population is distributed around zero. ${ }^{4,5}$ Anti-symmetry is present when the side which is bigger varies among individuals, creating a bimodal distribution for the differences. ${ }^{4,6}$ Fluctuating asymmetry has been used as a measure of developmental instability in environmentally stressed populations, and it has been determined that FA increases in direct proportion to environmental stress. ${ }^{7}$ Directional asymmetry is the consistent difference between a pair of skeletal structures, such that the larger metric consistently occurs on one side. ${ }^{4,8}$ Although most mammals have bilaterally symmetrical skulls, a common departure from this ideal symmetry is DA, which has been not only observed in wild animals ${ }^{9}$, but also in domestic species: pig, ${ }^{10,11}$ horses ${ }^{8,12,13}$ and sheep ${ }^{14}$ amongst others. Furthermore, heritability studies indicate that DA has a genetic basis ${ }^{1,15}$ so it may not necessarily be induced by mechanical stress.

Geometric morphometrics (GM) can quantify individual variation and asymmetry in geometric form (size and shape) of paired structures. ${ }^{16}$ Geometric morphometrics received

October 7, 2019

accepted after revision

January 13, 2020
DOI https://doi.org/

10.1055/s-0040-1702986. ISSN 2625-2325. (c) 2020 Georg Thieme Verlag KG
Stuttgart · New York

License terms

(1)(1) 
are useful tools to study shape, because they eliminate differences in size, location and orientation, unlike traditional morphometrics. ${ }^{7}$ The GM approach consists of landmarking photographic images (landmarks are anatomical points, topologically equivalent) of each specimen and creating mirror images of the right and left sides to form a consensus figure. ${ }^{17}$ Differences between landmarked points and consensus points are used to calculate Procrustes residuals as a measure of asymmetry for all landmarks, allowing shape variation to be partitioned into symmetric and asymmetric components. ${ }^{17}$

The Araucan horse is a breed from the Araucan Department, East Colombia, with an average weigh of $320 \mathrm{~kg}$, and a convex head profile. ${ }^{18}$ Predominantly used in cattle herding it is highly adapted to rough environmental conditions of that area. ${ }^{18,19}$

The objective of this study was to determine, by means of GM methods, whether DA appears in the skulls of the Araucan horse. More specifically, we investigated: (i) how are asymmetries expressed in the Araucan horse; (ii) and whether DA is higher in the neurocranium or the splanchnocranium.

Answers to these questions could also be an incentive to study skull asymmetries in other domestic mammals, a subject which only began to be studied during the last few years. Besides reporting the incidence of DA in the Araucan horse, the intention is to contribute to the few studies of skull shapes in animals, using GM.

\section{Materials and Methods}

\section{Population Studied}

A sample of 21 skulls of the Araucan horse breed was studied from different private collections in the Araucan savannah (East Colombia) during February 2018. Skulls were only from adult males. All skulls were generally well preserved. Some had pathological lesions (assessed on the basis of macroscopic examination) and this was an exclusion criterion because of the inability to determine precise anatomical points of reference.

\section{Data Acquisition}

A total of 16 two-dimensional homologous landmarks on the dorsal aspect of each skull ( - Table $\mathbf{1}$ and $\boldsymbol{-}$-Fig. $\mathbf{1}$ ) were used, 14 points of reference bilateral and 2 midline. We followed suggestions of previous studies and subdivided the skull into two units, the neurocranium and the splanchnocranium. ${ }^{20-22}$ Two sets of landmarks were used to define neurocranium and splanchnocranium, respectively. ${ }^{23}$ Within the data, landmarks 7 to 16 described the neurocranium, landmarks 1 to 6 the splanchnocranium.

Each skull was levelled on a horizontal plan, on its dorsal side ('face upward'). Image capture was then performed with a Nikon D70 digital camera (image resolution of $2,240 \times 1,488$ pixels) equipped with a Nikon AF Nikkor 28 to $200 \mathrm{~mm}$ telephoto lens, on the dorsal side. The camera was placed so that the focal axis of the camera was parallel to the horizontal plane and centred on the dorsal aspect of the skull. A scale was put over each specimen. The software TPSUtil v. $1.50^{24}$ was used to prepare and organize the images. Landmarks were digitized twice, using TPSDig v. $2.16 .^{24}$ To compare Procrustes to tangent space distances between individuals, the procedure using TPSSmall v. $1.29^{24}$ allowed capture of the nature and extent of skull shape deformations. It reflected a high degree of approximation of shapes in the sample (i.e. shape space) in relation to the reference shape (i.e., tangent space) $(r=0.999)$.

\section{Shape Asymmetry}

Coordinates were converted to pairs of Euclidian distances, between pairs of homologous landmarks on the left and right sides of the skull. A generalized full Procrustes fit was performed on two-dimensional landmark coordinates to extract shape information. Shape asymmetry of skulls was studied by superimposing the configurations of landmarks from each side of the skull using a Procrustes superimposition. ${ }^{25}$ After configurations were scaled to unit centroid size (CS computed as the square root of the sum of squared distances of all landmarks from the cen$\left.\operatorname{troid}^{16}\right)$, configurations were rotated around their centroid

Table 1 Landmarks used for the study of asymmetries in Araucan horse skull (dorsal aspect).

\begin{tabular}{|l|l|}
\hline 1. Widest part of right os incisivum & 9. Right foramen supraorbitale \\
\hline 2. Widest part of left os incisivum & 10. Left foramen supraorbitale \\
\hline 3. Starting point for right maxilla & $\begin{array}{l}\text { 11. Most caudal point of right processus zygomaticus ossis } \\
\text { temporalis }\end{array}$ \\
\hline 4. Starting point for left maxilla & $\begin{array}{l}\text { 12. Most caudal point of left processus zygomaticus ossis } \\
\text { temporalis }\end{array}$ \\
\hline 5. Most oral point of right crista facialis & 13. Starting point for right os occipitale \\
\hline 6. Most oral point of left crista facialis & 14. Starting point for left os occipitale \\
\hline $\begin{array}{l}\text { 7. Most oral point of right processus zygomaticus ossis } \\
\text { temporalis }\end{array}$ & 15. Middle of crista nuchae \\
\hline 8. Most oral point of left processus zygomaticus ossis temporalis & 16. Middle of fronto-nasal suture \\
\hline
\end{tabular}

Note: In total, 16 two-dimensional landmarks were used on the dorsal side of skull. Fourteen were bilateral and two (15 and 16$)$ were midline landmarks. All landmarks are considered to encompass elements of both neurocranium and splanchnocranium. Landmarks 7 to 16 describe the neurocranium, whereas landmarks 1 to 6 describe the splanchnocranium. 


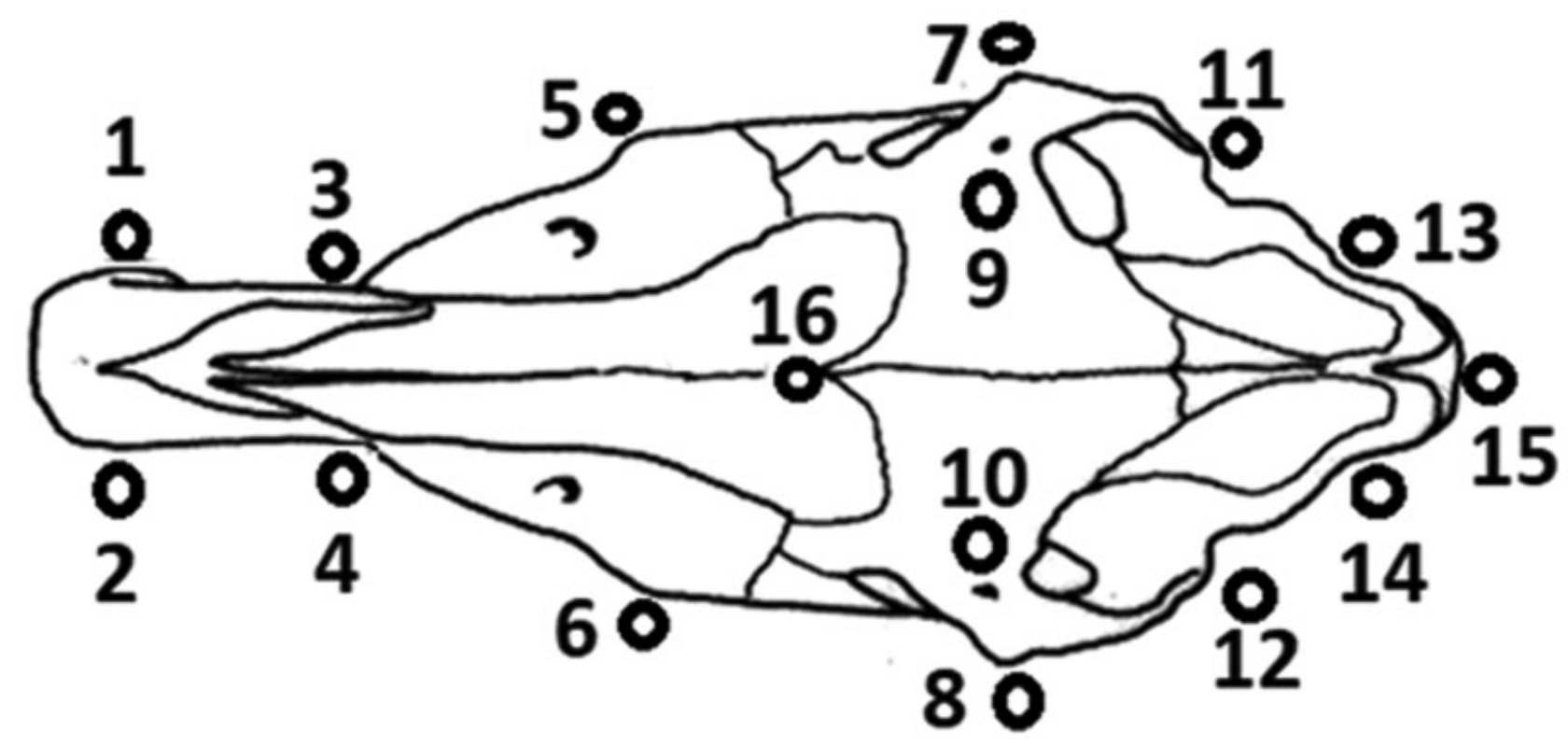

Fig. 1 Position on landmarks used for the study of asymmetries in horse skull (dorsal aspect). In total, 16 two-dimensional landmarks were used on the dorsal side of skull. Fourteen of them were bilateral and two were midline landmarks. All set was considered to encompass elements of both neurocranium and splanchnocranium.

(the point with average coordinates) (-Fig. 2). Finally, asymmetry was measured as the deviations between the bilateral pairs of the corresponding superimposed landmarks. ${ }^{26}$

\section{Intra-observer Error}

To establish the degree of error in the acquisition of the landmark series, we repeated the measurements twice on different days for all specimens. The measurement error was tested to verify whether asymmetry estimates were significantly larger than predicted due to intra-observer error alone.

\section{Statistical Analysis}

The effect of allometry was verified using the multivariate regression of shape (Procrustes coordinates) on the CS $\left(\log _{10^{-}}\right.$ transformed). Centroid size was treated here as a proxy for the general skull size. A two-way, mixed-model analysis of variance (ANOVA) was performed separately on each of the characters including two replicas. In this analysis, 'sides' is a fixed effect, whereas 'individual' is a random effect. Individual variation in each character is partitioned into DA (the main effect due to 'sides' at a population level), individual variation in size and shape (the main effect due to 'individual'), non-DA (FA, the "sides-by-individual" interaction) and

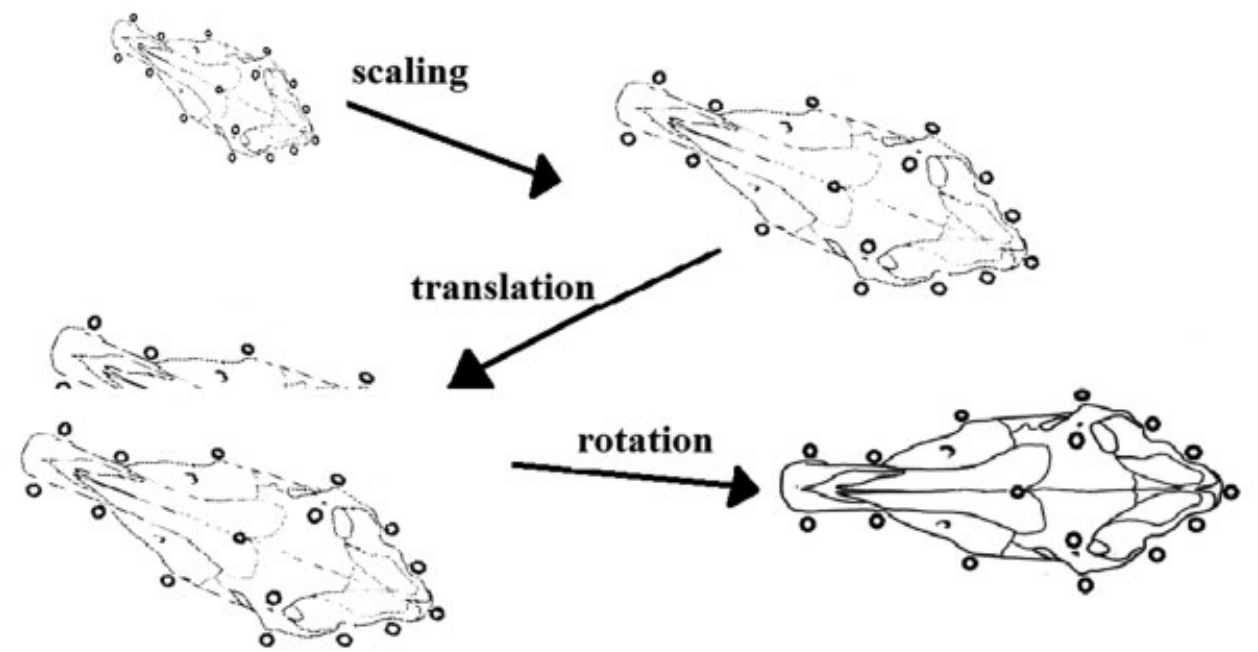

Fig. 2 Summary of Procrustes superimposition. Components of variation other than shape are eliminated by scaling to the same size, translating to the same location of centroids and rotating to an overall best fit of corresponding landmarks. 
Table 2 Variance explained for each principal component (PC).

\begin{tabular}{|l|l|l|l|}
\hline PC & Eigenvalues & \% of variance & $\begin{array}{l}\text { Cumulative } \\
\text { variance (\%) }\end{array}$ \\
\hline 1 & 0.00012 & 45.21 & 45.21 \\
\hline 2 & $3.5 \mathrm{E}-05$ & 13.23 & 58.44 \\
\hline 3 & $2.46 \mathrm{E}-05$ & 9.30 & 67.75 \\
\hline 4 & $1.93 \mathrm{E}-05$ & 7.28 & 75.03 \\
\hline 5 & $1.68 \mathrm{E}-05$ & 6.36 & 81.39 \\
\hline 6 & $1.36 \mathrm{E}-05$ & 5.14 & 86.54 \\
\hline 7 & $8.69 \mathrm{E}-06$ & 3.28 & 89.82 \\
\hline 8 & $7.56 \mathrm{E}-06$ & 2.85 & 92.68 \\
\hline 9 & $5.25 \mathrm{E}-06$ & 1.98 & 94.67 \\
\hline 10 & $4.36 \mathrm{E}-06$ & 1.64 & 96.31 \\
\hline 11 & $4.07 \mathrm{E}-06$ & 1.53 & 97.85 \\
\hline 12 & $2.82 \mathrm{E}-06$ & 1.06 & 98.92 \\
\hline 13 & $2.06 \mathrm{E}-06$ & 0.77 & 99.69 \\
\hline 14 & $8 \mathrm{E}-07$ & 0.30 & 100 \\
\hline
\end{tabular}

Note: First two PCs explained $58.4 \%$ of the total variance observed $(\mathrm{PC} 1+\mathrm{PC} 2=45.2 \%+13.2 \%)$.

measurement error. Degrees of freedom for the shape ANOVA were the degrees of freedom for each of the effects multiplied by the number of landmark coordinates, minus four. Asymmetric components (DA and FA) were analysed for modularity. A principal component analysis (PCA) was done to reduce the set of Procrustes coordinates to a smaller set that still contains most of the information in the large set. To compare integration strengths, the measure of covariance coefficients-a scalar measure of the strength of association between the coordinates of two sets of landmarks $-{ }^{27}$ were used to compare subsets of landmarks within two blocksneurocranium and splanchnocranium-that form the skull. Finally, partial least squares (PLS) reduced the number of variables being observed so patterns were more easily observed in the data. This is similar to the PCA, but it uses a linear regression model. Morphometric analyses were performed with MorphoJ v. 1.06c software. ${ }^{28}$

\section{Results}

\section{Allometry}

The relationship between skull shape and size remained undefined. The multivariate regression of the Procrustes coordinates on $\log _{10}$-transformed CS showed that allometry was not significant $(p=0.561$, permutation test with 9,999 random permutations), $\log _{10}$-transformed CS accounting only for $3.87 \%$ of the total shape variance. This lack of allometry made unnecessary a size-correction for further analysis.

\section{Asymmetries}

Significant differences were seen for individual variation, FA and DA (-Table 2). A multivariate analysis of variance test confirmed the presence of FA and DA $(p<0.05)$. Directional asymmetry variance of shape was significantly larger (54.9\%) than the variance due to measurement error and FA (-Table 3). First two principal components (PC) from PCA explained $58.4 \%$ of the total variance observed (PC1 + PC2 $=45.2 \%+13.2 \%)$. On PC1, landmarks located both on neurocranium (10, 11 and 12) and on splanchnocranium (pairs $1-2,3-4$ and 5-6) were in strong support for the explanation of the asymmetry observed ( - Table 4 ). Most discriminant landmarks on PC2 were mainly on the neurocranium (pairs 7-8, 11-12 and 13-14) (-Table 4). The most discriminant landmarks on PC1 presented a clear lateral displacement, mainly towards right (except for paired landmarks 1 and 2, located on the most rostral part of the splanchnocranium) (-Fig. 3).

\section{Modularity}

The RV coefficients of two-modules subdivision (neurocranium and splanchnocranium) for the asymmetric data were the lowest of any possible partitions amongst the configuration $(0.660, p<0.001)$; thus, two modules explained general variation in the skull.

Table 3 ANOVA-results for size (A) and shape (B).

\begin{tabular}{|l|l|l|l|l|l|}
\hline A) & Sums of squares & Mean squares & Degrees of freedom & $F$ & $p$-Value \\
\hline Effect & 400092.3 & 20004.6 & 20 & 0.12 & 1 \\
\hline Individual & 3235039.0 & 161751.9 & 20 & & \\
\hline Error & \multicolumn{5}{|l|}{} \\
\hline B) & Sums of squares & Mean squares & Degrees of freedom & $F$ & 6.73 \\
\hline Effect & 0.058621 & 0.000209 & 280 & 9.91 & $<$-Value \\
\hline Individual & 0.004314 & 0.000308 & 14 & 2.51 & $<0.0001$ \\
\hline Side & 0.008706 & $3.11 \mathrm{E}-05$ & 280 & & $<0.0001$ \\
\hline Individual*Side & 0.006944 & $1.24 \mathrm{E}-05$ & 560 & & \\
\hline Error & & & & \\
\hline
\end{tabular}

Abbreviation: ANOVA, analysis of variance.

Note: Directional asymmetry ('Side') of shape was significantly larger than the variance expected due to measurement error and fluctuating asymmetry ('Individual*side'), being a 54.9\% larger. Sums of squares and mean squares are in units of Procrustes distances (dimensionless). 
Table 4 Loadings for principal components (PC) 1 and 2 $(P C 1+P C 2=48.6 \%+11.4 \%)$ for each landmark.

\begin{tabular}{|c|c|c|}
\hline & PC1 & PC2 \\
\hline $\mathrm{x} 1$ & 0.0292 & 0.0427 \\
\hline y1 & -0.2083 & -0.0884 \\
\hline$x 2$ & -0.0292 & -0.0427 \\
\hline y2 & -0.2083 & -0.0884 \\
\hline$x 3$ & 0.2682 & 0.0356 \\
\hline y3 & 0.0657 & 0.0350 \\
\hline$x 4$ & -0.2682 & -0.0357 \\
\hline y4 & 0.0657 & 0.0350 \\
\hline$x 5$ & 0.2357 & -0.2860 \\
\hline y5 & -0.1788 & 0.0554 \\
\hline$x 6$ & -0.2357 & 0.2860 \\
\hline y6 & -0.1788 & 0.0554 \\
\hline x7 & -0.0078 & 0.2165 \\
\hline y7 & 0.0376 & 0.0447 \\
\hline$x 8$ & 0.0078 & -0.2165 \\
\hline y8 & 0.0376 & 0.0447 \\
\hline$x 9$ & -0.0318 & 0.1304 \\
\hline y9 & 0.3231 & -0.1696 \\
\hline $\mathrm{x} 10$ & 0.0318 & -0.1304 \\
\hline $\mathrm{y} 10$ & 0.3231 & -0.1696 \\
\hline $\mathrm{x} 11$ & 0.2111 & 0.4677 \\
\hline y11 & -0.1707 & -0.1641 \\
\hline$x 12$ & -0.2111 & -0.4677 \\
\hline y12 & -0.1707 & -0.1641 \\
\hline$x 13$ & -0.1494 & 0.0096 \\
\hline y13 & -0.0336 & 0.2192 \\
\hline $\mathrm{x} 14$ & 0.1494 & -0.0096 \\
\hline $\mathrm{y} 14$ & -0.0336 & 0.2192 \\
\hline $\mathrm{x} 15$ & 0 & 0 \\
\hline y15 & -0.0809 & 0.1666 \\
\hline $\mathrm{x} 16$ & 0 & 0 \\
\hline y16 & 0.4109 & -0.0312 \\
\hline
\end{tabular}

Note: Highest absolute loadings $(>[0.2])$ appear in bold. Most discriminant landmarks on PC1 were 1, 2, 3, 4, 5, 6, 9, 10, 11, 12 and 16. Most discriminant landmarks on PC2 were 5, 6, 7, 8, 11, 12, 13 and 14. Landmarks on - Table 1.

\section{Integration of Neurocranium and Splanchnocranium}

Partial least squares-within configuration was made for the asymmetric dataset and considered two-modules subdivision (neurocranium and splanchnocranium) (-Fig. 4). First PLS axes (PLS1) accounted for $94.8 \%$ of the total squared covariance between the neurocranium and the splanchnocranium (singular value $=0.00005327 ; p<0.001)$ ( - Fig. 5), so the hypothesis of no covariation was rejected. The highest integration was for splanchnocranium landmarks: maxi- mum scores of PLS1 were associated with os incisivum, maxilla and crista facialis (landmarks 1 to 6), although correlation between the neurocranium and the splanchnocranium was high and statistically significant $(r=0.878)$. These results suggest that most of the covariation between the neurocranium and the splanchnocranium is due to differences in the topography of the distal face.

\section{Discussion}

In this study, we assessed significance of the cranial components on Araucan horse skulls, by means of GM, and evaluated the degree of asymmetries after other sources of variation are accounted for, once the size effect was eliminated. Relative magnitudes of the components of bilateral variation (FA, DA and measurement error) were assessed and compared, and their interrelationships evaluated through multivariate analysis. The DA component was significantly higher than FA ( $>50 \%$ of the total variation).

A major methodological problem in interpreting patterns of bilateral variation is that more than one type of asymmetry may occur simultaneously in a population. When the focus of a study is to compare levels of developmental noise, DA may obscure the effect of FA, although the former component might also reflect developmental instability. 29,30 Measurement error is another concern in asymmetry studies, because differences in values of bilateral traits are usually small, and also because asymmetry analyses are comparisons of variances, error becomes a key issue.

Principal component analysis suggests the existence of a localized component for left DA on splanchnocranium. This is consistent with previous results obtained from other domestic mammals. ${ }^{31-35}$

The high magnitude and precise expression of DA in our skull samples imply a behavioural lateralization. Mechanical forces could be a possible cause of this symmetry modification; that is, the dominance of one side may be determined by a right-sidedness in mastication, because skeletal structures undergo remodelling during development. In fact, studies on bones have shown that the trabecular architecture maintains its shape but adapts according to mechanical stimuli. ${ }^{36,37}$ Therefore, craniofacial morphology would respond to changes in mechanical stimuli. More specifically, the morphology of the skull, or at least part of it, could change according to variations in mechanical stimuli during mastication to compensate for structural stress. The dorsal aspect of the muzzle would have a tendency to shift left to compensate for the right-lateralized mastication, for mandible movement during chewing, and thus for greater mechanical forces on one side than on the other. $^{38}$

An oriented asymmetry of the skull could therefore be determined by a continued increase in use of one side of the mandible in respect to the other. ${ }^{38}$ Evidently, mechanical forces of different strength during mastication would affect the morphology and internal structure of the bony structure. This is particularly true at those parts where masticatory muscles are attached, as the processes of bone formation and 


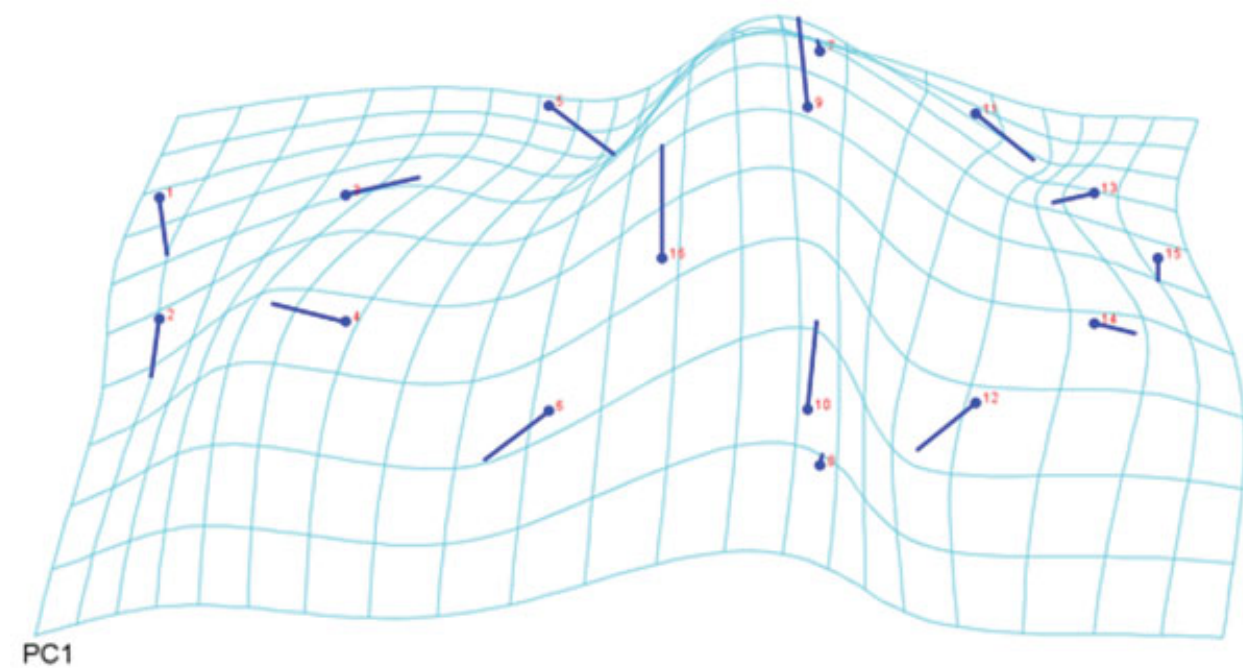

Fig. 3 Deformation grid for principal component 1 illustrating the mean shape differences. A righward shift of cranial bones was observed, mainly on splanchnocranium (1 to 6). Landmarks are described on -Table $\mathbf{1}$. Shape differences are linearly extrapolated by factor 0.2 .

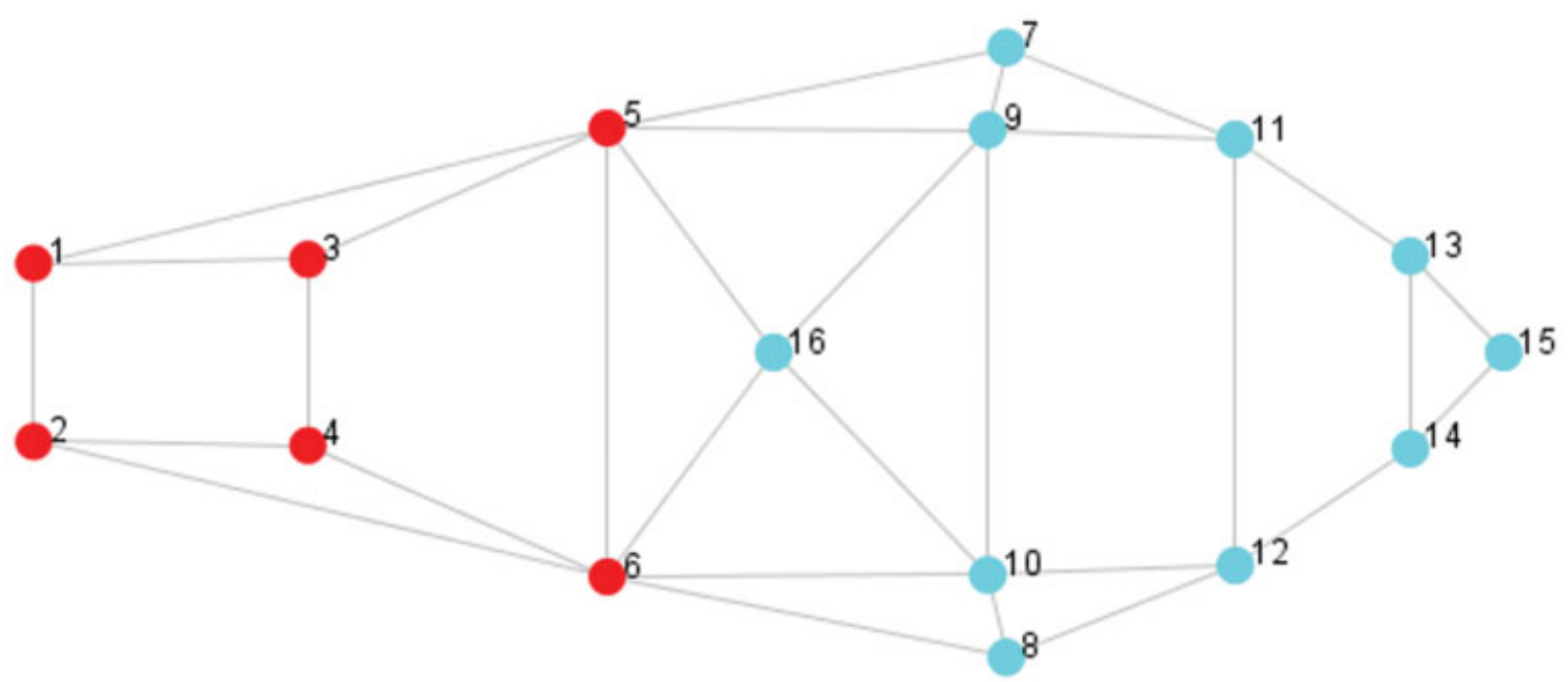

Fig. 4 Two-module subdivision (neurocranium and splanchnocranium).

resorption are influenced by mechanical stressors. ${ }^{39}$ Bone morphology would be regulated to maintain strength. ${ }^{39}$ Many studies show that the morphology of the mandible is affected by the masticatory function. ${ }^{11,39-41}$ In humans, extreme lateralization of behavioural gestures, such as handedness, has been studied for over a century such as acquired directional mandibular asymmetries have been described because of chewing side preference. ${ }^{42}$ Although skeletal asymmetries have been studied most extensively in humans, correlations between DA and lateralization appear to occur in many vertebrates. ${ }^{12,35,43-46}$ This link between masticatory lateralization and craniofacial asymmetry seems the most plausible explanation for the data we obtained; this also, because most of the masticatory muscles insert at the highest plastic anatomical points detected: buccinator (pars buccalis) and masseter (pars superficialis). However, in the Araucan horse, this asymmetry appears not to be a factor diminishing individual life expectations, as a wide age spectrum (assessed by occlusal molar wearing-data not presented here) was collected.

The search for similar patterns in other horse breeds would clarify the relevance of asymmetries as a measure of developmental stability, and DA as an adaptative trait. To complement these investigations, the study of mechanical stimuli (such as grinding teeth and use of salt bite blocks) and ingesta-specific properties (such as abrasiveness) should be studied.

\section{Conclusions}

Directional shape asymmetry in Araucan horse skulls was significant using GM methods, with splanchnocranium presenting the highest contribution to this asymmetry. It is suggested that this lateralization is due to the direction of 


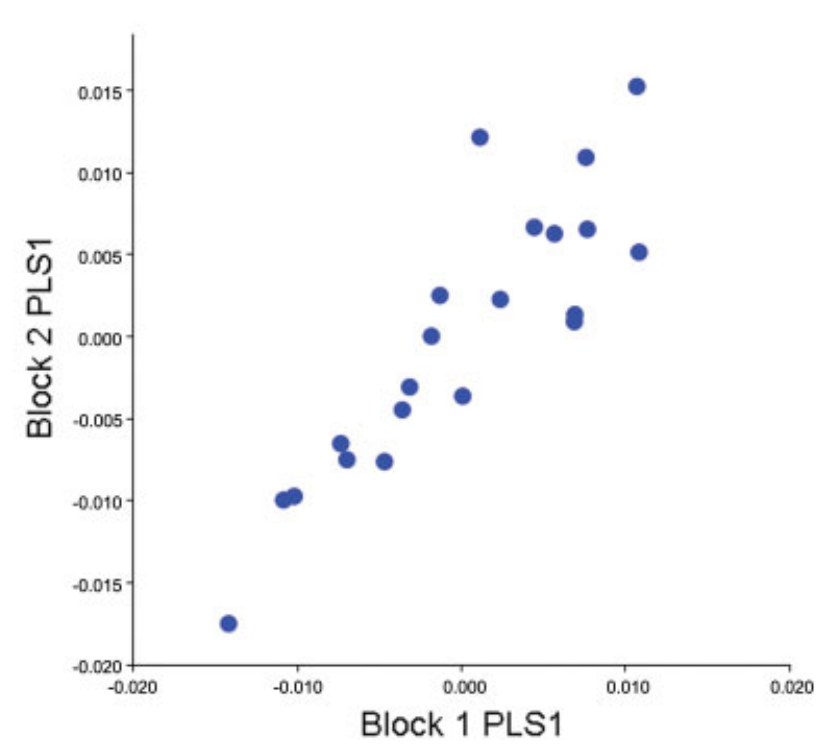

Fig. 5 Distribution of specimens in the scatterplot of partial least square 1 (PLS1). Variation within neurocranium (Block 1) presented at $\mathrm{x}$-axis and variation within splanchnocranium (Block 2 ) is at $y$-axis. First PLS axes (PLS1) accounted for $94.8 \%$ of the total squared covariance between both modules (singular value $=0.00005327$, $p<0.001)$.

jaw movement during chewing, and thus an adaptive consequence of greater mechanical forces on one side than on the other.

The results of this study raise future questions not only about the influence of skull biomechanics on its asymmetrical development but also about how ingesta-specific properties (such as abrasiveness) and management can influence this response.

\section{Authors' Contributions}

All authors analysed the data and drafted the manuscript. PMPC designed the study, and directed implementation and data collection. ASC, RCG and FAM collected the data, and ASC provided necessary logistical support.

Funding

None.

Conflict of Interest.

None to declare.

\section{Acknowledgments}

The authors acknowledge all the facilitations offered by Araucan farmers. We also thank anonymous referees for careful reading of the manuscript and helpful comments.

\section{References}

1 Amik T. Of mice, mothers and mirror-images: testing relationships between asymmetry and fecundity. Thesis. University of Guelph; 2001:53

2 Rasskin-Gutman D. Organized mayhem in Bilateria Baupläne: symmetry and animal complexity. Coloquios Paleontol 2003;1 (01):559-567
3 Cocilovo JA, Varela HH, Quevedo S. La asimetría bilateral y la inestabilidad del desarrollo. Rev Argent Antropol Biol 2006;8(01): 121-144

4 Auffray JC, Debat V, Alibert P. Shape asymmetry and developmental stability. In: Mark A.J. Chaplain, G.D. Singh JCM, eds. On Growth and Form: Spatio-Temporal Pattern Formation in Biology. New York: John Wiley and Sons Ltd; 1999:309-324

5 Angelopoulou MV, Vlachou V, Halazonetis DJ. Fluctuating molar asymmetry in relation to environmental radioactivity. Arch Oral Biol 2009;54(07):666-670

6 Parés-Casanova PM, Kucherova I. Horn antisymmetry in a local goat population. Int J Res Agric Food Sci 2013;1(02):12-17

7 López-Romero F, Zúñiga G, Martínez-Jerónimo F. Asymmetric patterns in the cranial skeleton of zebrafish (Danio rerio) exposed to sodium pentachlorophenate at different embryonic developmental stages. Ecotoxicol Environ Saf 2012;84:25-31

8 Leśniak K. Directional asymmetry of facial and limb traits in horses and ponies. Vet J 2013;198(01, Suppl 1):e46-e51

9 Kharlamova AV, Trut LN, Chase K, Kukekova AV, Lark KG. Directional asymmetry in the limbs, skull and pelvis of the silver fox (V. vulpes). J Morphol 2010;271(12):1501-1508

10 Parés-Casanova PM, Esteve-Puig C. Directional and fluctuating asymmetries in domestic pig skulls. Research 2014;1(828):1-5

11 Parés-Casanova PM. Age-dependent mandibular asymmetries in domestic pigs. Research 2014;1(797):4-7

12 Wilson GH, McDonald K, O'Connell MJ. Skeletal forelimb measurements and hoof spread in relation to asymmetry in the bilateral forelimb of horses. Equine Vet J 2009;41(03):238-241

13 Parés-Casanova PM. Harmonic analysis of equine hoof form and its matched symmetry. Research 2014;1(889):1-4

14 Parés-Casanova PM, Bravi R. Directional and fluctuating asymmetries in domestic sheep skulls. J Zool Biosci Res 2014;2(03):11-17

15 Carter AJR, Osborne E, Houle D. Heritability of directional asymmetry in Drosophila melanogaster. Int J Evol Biol 2009; 2010:759159. Doi: 10.4061/2009/759159

16 Bookstein FL. Morphometric Tools for Landmark Data: Geometry and Biology. Cambridge University Press, ed.). Cambridge; 1991. Doi: $10.1002 / \operatorname{sim} .4780120711$

17 Mardia KV, Bookstein FL, Moreton IJ. Statistical assessment of bilateral symmetry of shapes. Biometrika Trust 2000;87(02): 285-300

18 Salamanca-Carreño A, Monroy N, Parés-Casanova PM, Crosby RA. Aporte a la evaluación para la preservación del caballo Criollo Araucano en Colombia. Zootec Trop 2015;33(04):317-325

19 Salamanca-Carreño A, Parés-Casanova PM, Crosby RA, Monroy N. Análisis biométrico del caballo Criollo Araucano. Arch Zootec 2017;66(253):267-278

20 Klingenberg CP. Developmental Constraints, Modules, and Evolvability. In: Variation. Elsevier; 2005:219-247

21 Hallgrímsson B, Brown JJ, Ford-Hutchinson AF, Sheets HD, Zelditch ML, Jirik FR. The brachymorph mouse and the developmental-genetic basis for canalization and morphological integration. Evol Dev 2006;8(01):61-73

22 Vallejo RM, Guerrero JA, González-Cózatl FX. Patterns of differentiation and disparity in cranial morphology in rodent species of the genus Megadontomys (Rodentia: Cricetidae). Zool Stud 2017; 56:14. Doi: 10.6620/ZS.2017.56-14

23 Von den Driesch A. A Guide to the Measurement of Animal Bones from Archaeological Sites. Massachusetts: Peabody Museum of Archaeology and Ethnology Harvard University; 1976

24 Rohlf FJ. The tps series of software. Hystrix 2015;26(01):9-12

25 Klingenberg CP, McIntyre GS, Zaklan SD. Left-right asymmetry of fly wings and the evolution of body axes. Proc Biol Sci 1998;265 (1402):1255-1259

26 Webster M, Sheets HD. A practical introduction to landmark-based geometric morphometrics. In: Alroy J, Hunt G, eds. Quantitative Methods in Paleobiology. The Paleontological Society; 2010: 163-188 
27 Klingenberg CP. Morphometric integration and modularity in configurations of landmarks: tools for evaluating a priori hypotheses. Evol Dev 2009;11(04):405-421

28 Klingenberg CP. MorphoJ: an integrated software package for geometric morphometrics. Mol Ecol Resour 2011;11(02):353-357

29 Rowe L, Repasky RR, Palmer AR. Size-dependent asymmetry: fluctuating asymmetry versus antisymmetry and its relevance to condition-dependent signaling. Evolution 1997;51(05):1401-1408

30 Klingenberg CP, McIntyre GS. Geometric morphometrics of developmental instability: analyzing patterns of fluctuating asymmetry with Procrustes methods. Evolution 1998;52(05):1363-1375

31 Bartosiewicz L, Van Neer W, Lentacker A. Metapodial asymmetry in draft cattle. Int J Osteoarchaeol 1993;3(02):69-75

32 Ocal MK, Sevil F, Parin U. A quantitative study on the digital bones of cattle. Ann Anat 2004;186(02):165-168

33 Morgante M, Gianesella M, Versace E, et al. Preliminary study on metabolic profile of pregnant and non-pregnant ewes with high or low degree of behavioral lateralization. Anim Sci J 2010;81(06): 722-730

34 Austin NP, Rogers LJ. Limb preferences and lateralization of aggression, reactivity and vigilance in feral horses, Equus caballus. Anim Behav 2012;83(01):239-247

35 Gourso C, Düpjan S, Tuchscherer B, Lisette MCL. Behavioural lateralization in domestic pigs (Sus scrofa)-variations between motor functions and individuals. Laterality, Asymmetries Brain. Behav Cogn 2018;23(05):576-598

36 Auerbach BM, Ruff CB. Limb bone bilateral asymmetry: variability and commonality among modern humans. J Hum Evol 2006;50 (02):203-218
37 Blackburn A. Bilateral asymmetry of the humerus during growth and development. Am J Phys Anthropol 2011;145(04):639-646

38 Dias GJ, Cook RB, Mirhosseini M. Influence of food consistency on growth and morphology of the mandibular condyle. Clin Anat 2011;24(05):590-598

39 Hems T, Tillmann B. Tendon entheses of the human masticatory muscles. Anat Embryol (Berl) 2000;202(03):201-208

40 Parés-Casanova PM. Conservative neural symmetry of the caprine mandible. Korean J Vet Res 2013;53(04):1-4

41 Parés-Casanova PM. Existence of mandibular directional asymmetry in the European wild boar (Sus scrofa Linnaeus, 1758). J Morphol Sci 2014;31(04):1-5

42 Marado LM, Silva AM. Dental and oral nonmetric traits in a Coimbra reference sample: testing intrasample chronological and spatial variation. Archaeol Anthropol Sci 2018;10(05): 1165-1177

43 Reeves NM, Auerbach BM, Sylvester AD. Fluctuating and directional asymmetry in the long bones of captive cotton-top tamarins (Saguinus oedipus). Am J Phys Anthropol 2016;160 (01):41-51

44 Brown C, Magat M. Cerebral lateralization determines hand preferences in Australian parrots. Biol Lett 2011;7(04):496498

45 Hackert R, Maes LD, Herbin M, Libourel PA, Abourachid A. Limb preference in the gallop of dogs and the half-bound of pikas on flat ground. Laterality 2008;13(04):310-319

46 Leśniak K, Whittington L, Mapletoft S, et al. The influence of body mass and height on equine hoof conformation and symmetry. J Equine Vet Sci 2019;77:43-49 